\title{
Inherent and coerced gradability across categories: manipulating pragmatic halos with sorta $^{*}$
}

\author{
Curt Anderson \\ Michigan State University
}

\begin{abstract}
In this paper I provide an analysis of the English hedges sorta and kinda, which show a cross-categorial distribution and can induce gradability with nongradable predicates. I analyze sorta and kinda as degree words and provide a formal analysis of their behavior. With gradable predicates, these exhibit behavior similar to other degree words such as very, but with non-gradable predicates, a mismatch of logical type forces the predicate to typeshift to a gradable type, making available a degree argument that represents imprecision. The analysis is developed using Morzycki's (2011) implementation of Lasersohnian pragmatic halos (Lasersohn 1999), and presents a case study in how gradability may be coerced from nongradable expressions.
\end{abstract}

Keywords: scales, gradability, imprecision, vagueness, modification, alternative semantics, pragmatic halos

\section{Introduction}

Hedges such as sorta, kinda, more or less, and rather (to name a few) are a pervasive but poorly understood aspect of language. They provide a link between semantics and pragmatics, with a foot anchored securely in each domain. Although the target of early forays into formal semantics (Lakoff 1973), hedges have been studied much less compared to other phenomena that cut across semantics and pragmatics, such as polarity items. This paper presents a case study on sorta (and its sibling kinda) with the intent of making clear some of its lexical semantic properties. Chief among the properties studied will be its cross-categorial nature and how it can modify adjectives as well as verbs, as in (1) and (2), respectively, and even in some cases nouns, as in (3). Also of interest in this study will be the source of the gradability for various predicates, and why sorta has the effect of making verbs and nouns conceptually gradable.

* I would like to thank Marcin Morzycki, Cristina Schmitt, Alan Munn, Alan Beretta, Karthik Durvasula, Jessica Gamache, Greg Johnson, Hannah Forsythe, and Adam Gobeski for their comments and suggestions, as well as the audiences of SALT 23 at the University of California Santa Cruz, the 37th Penn Linguistics Colloquium, and ConSOLE XXI at the University of Potsdam.

(C)2013 Curt Anderson 
(1) a. It's sorta hard to explain.

b. a lot of young people think their parents are starting to seem, you know, sorta old and over the hill... 1

c. Gas is sorta expensive. ${ }^{2}$

(2) a. But I can't see how that Diaz just sorta evaporated, like some kid's bad dream. ${ }^{3}$

b. ...running on concrete and accidentally sorta kicked the ground. ${ }^{4}$

(3) a. a sorta fairytale ${ }^{5}$

b. I may be your sorta mom now and I'm practically a child myself. ${ }^{6}$

This has broader reaching consequences than simply the lexical semantics of sorta. I argue here that there are at least two sources of gradability that sorta diagnoses: the inherent gradability of scalar adjectives such as tall, but also coerced gradability derived from sets of alternatives modeling Lasersohnian pragmatic halos. This has the further consequence of making pragmatic halos part of the compositional semantics, a move that follows Morzycki (2011). The central claim of the paper will be that sorta operates as a degree word, but in constructions without a lexicalized degree argument, a typeshift occurs that bestows a degree argument upon a nongradable predicate.

The paper proceeds as follows. Section 2 lays out the core data I wish to account for, with section 2.1 explaining the observations of sorta with adjectives, and section 3 laying out the data with verbs and nouns. Section 4 presents the theoretical background Lasersohn's (1999) pragmatic halos, and Morzycki's (2011) implementation in an alternative semantics. My analysis is presented in section 5.

But first, a note on conventions is necessary. Throughout the paper, I use sorta to refer to the adverbial element in examples (1-3) above. I write this element as sorta rather than sort of in order to emphasize its difference from the noun sort (i.e., a sort of $d o g$ ). Sorta is often reduced in speech, which the writing is also meant to reflect, but there may be cases where I have written sorta but it is not reducible for typical American English speakers. Finally, I take sorta to be equivalent to kinda (kind of, more standardly); insofar as I can tell, there is no semantic difference between the two. Some speakers do prefer kinda over sorta, for seemingly apparent stylistic reasons, so for examples where sorta is used, kinda can be substituted for those speakers.

1 Corpus of Contemporary American English (COCA) (Davies 2008)

$2 \mathrm{http}: / /$ www.tripful.com/q/v/257295/i_want_to_move_to_south_nm_or_az_advice_please

3 COCA

4 http://www.kongregate.com/forums/2/topics/97092?page=2

5 Tori Amos, "A Sorta Fairytale.” Epic/Sony BMG. (song lyrics)

6 Modern Family, “The Future Dunphys." ABC. (from a popular TV show) 
Inherent and coerced gradability

\section{Sorta, gradable adjectives, and other non-gradable predicates}

\subsection{Sorta and adjectives}

Sorta readily appears with gradable adjectives, and is able to combine with adjectives in the positive as in (4), as well as the comparative in (5), and constructions involving too and enough as in examples (6a-b). In this way, sorta looks like a degree word like very or slightly, which can also appear in many of these same environments.

(4) a. Bill is sorta tall.

b. Gas is sorta expensive.

a. She's sorta more intelligent than he is.

b. After losing a lot of weight I do feel sorta taller. ${ }^{7}$

a. I would cry but I'm sorta too angry... ${ }^{8}$

b. They are sorta old enough to appreciate it. ${ }^{9}$

If sorta is a degree word, we might also expect it to be an answer to howquestions. Example (7) shows that this is possible.

(7) How tall is your friend Bill? Sorta tall.

The natural interpretation of sorta here also suggests that it is degree-related. For instance, example (4a) claims that the individual Bill falls along the tallness scale, a meaning which is comparable to the sense of another degree word like very. The interpretation here also makes reference to a contextually defined standard; sort of tall intuitively asserts that an individual holds a degree of height close to the standard for being tall. Again, this is comparable to a degree word like very, which asserts that an individual holds a height far above the standard.

However, sorta differs from other degree words in being able to combine with non-gradable predicates as well, as in (8). What's important to note here, however, is that sorta loses its degree sense. (8a) doesn't assert a degree along a scale of pregnancy (because there is no scale), but involves a shift in meaning, one from actual pregnancy to passing the test for pregnancy. This shift in meaning can be aptly paraphrased with an approximative such as close to or like, and the approximative asserting closeness to the 'normal' meaning of the word: being sorta pregnant is like being pregnant in passing certain tests for pregnancy, while being sorta extinct is being very close to being extinct.

7 http://facepunch.com/showthread.php?t=1180165

8 http://firewifeelly.com/2011/02/19/i-would-cry-but-im-sorta-too-angry/

9 http://westcoastmuthas.com/2013/07/29/are-we-there-yet/ 
(8) a. I've been sorta pregnant four times. Being sorta pregnant sorta sucks. It's like you're late, you test early, you see two lines, you go for a blood test, you're pregnant, and then it's JUST KIDDING! $!^{10}$

b. It's sad [Chinese river dolphins are] (sorta) extinct. They're such cool critters. ${ }^{11}$

Summarizing, sorta has a clear degree use with gradable adjectives, but can be used with non-gradable adjectives as well. When used with non-gradable adjectives, sorta-modified predicates undergo a meaning shift towards something approximating the modified predicate.

\section{Sorta and other non-gradable predicates}

Sorta can combine with other non-gradable predicates as well. Chief among these are verbs, but for some speakers, nouns are possible as well. Like cases involving non-gradable adjectives, sorta with a verb also involves a meaning shift and can be paraphrased with an approximative. The role of sorta here is to assert some conceptual closeness to what is being modified.

(9) a. I sorta kicked the ground.

'I did something like kicking the ground.'

b. He sorta swam over to the boat.

'He did something that was like swimming over to the boat.'

The use of sorta with nouns differs from the nominal sort, as demonstrated with the contrasts in (10-11). ${ }^{12}$ A sort of fairytale is a type of fairytale, but a sorta fairytale can be taken to mean something that is only like a fairytale in some respect. Similarly, although a Porsche is a sort of car, it most definitely is not a sorta car.

a. a sort of fairytale

'a type of fairytale'

b. a sorta fairytale 'almost but not a fairytale'

(11) a. A Porsche is a sort of car.

b. * A Porsche is a sorta car.

$10 \mathrm{http} / / /$ stowedstuff.com/2012/12/sorta-pregnant.html

$11 \mathrm{http}: / /$ clockworkstamps.deviantart.com/art/Baiji-151769205

12 Some speakers have trouble with sorta as a noun modifier. 
Important to point out is that sorta weakens the entailments of what it modifies; there is no entailment from sorta $V$ to $V$, where $V$ is a verb. Trying to force a contradiction shows that sorta is able to weaken the entailments of the verb phrase (Bolinger 1972). This shows that there are semantic, truth-conditional consequences involved with this modifier.

(12) a. He swam over to the boat. *That is to say, he didn't really swim.

b. He sorta swam over to the boat. That is to say, he didn't really swim.

(13) a. He kicked the ball. *That is to say, he didn't really kick it.

b. He sorta kicked the ball. That is to say, he didn't really kick it.

Finally, sorta with non-gradable predicates has the intuitive feeling of gradability. Constructions with sorta involve locating two predicates (sorta $V$ and $V$ ) along a scale of resemblance, with one predicate holding a lesser degree of resemblance to the other. This is a derived notion of gradability. The gradability involved here with non-gradable predicates isn't inherent to the lexical item itself (as it is with a gradable predicate such as tall), but rather is external to the predicate.

\subsection{Summary}

The observations in the previous sections bring up several points that an analysis of sorta must account for. The first point regards the cross-categorial nature of sorta. Why is it that sorta can appear with words and phrases of several lexical categories (adjectives, nouns, verbs)? What would sorta have to do in order to be used with categories that are often thought to have different semantics? And with regards to the semantics of gradability, how does sorta induce gradability where it did not arise before? I address these questions in section 5, but first take time to introduce useful background assumptions in the upcoming section.

\section{Pragmatics halos and alternative semantics}

\subsection{Halos}

Lasersohn (1999) observes that many natural language expressions can be used licitly even in situations where they would be false, strictly speaking. For instance, consider the utterance in (14) below. Under normal circumstances, (14) can be uttered even if there are a handful of night owls still awake. Lasersohn notes that the few people still awake at midnight in this situation don't seem to matter for the licitness of (14); even though it's false that the townspeople are asleep (some of them are awake, after all), the sentence is still pragmatically acceptable. The conclusion to draw from 
this is that hearers afford other speakers what Lasersohn calls "pragmatic slack" speakers are allowed a degree of sloppiness in their speech. The hearer affords the speaker of (14) pragmatic slack in how the townspeople is to be interpreted; although a few people awake at midnight do count semantically for the truth conditions of (14), they are pragmatically ignorable exceptions.

(14) The townspeople are asleep. (uttered at midnight)

This isn't confined solely to definite plural NPs. Similar behavior can be demonstrated with other things: with time (where (15) can be uttered if it's not exactly 3 o'clock); with a quantifier such as everyone, as in example (16), even if a few students are missing; and with predicates such as spherical in (17), even though very few things are perfectly spherical. Pragmatic slack is afforded quite regularly.

(15) It's 3 o'clock. (uttered at 2:58pm)

(16) Ok, everyone is here. (uttered by a professor at the start of class when a few students are absent)

(17) The earth is spherical.

Lasersohn proposes that certain linguistic expressions have surrounding them a "pragmatic halo" of pragmatically ignorable differences. 3 o'clock (for instance) might have a halo that includes times five minutes before and five minutes after 3 o'clock. As long as the truth of the matter falls within the halo, the utterance will be licit, and (15) is licit because the true time, $2: 58 \mathrm{pm}$, is within the pragmatic halo of $3 \mathrm{pm}$. Similarly, although the Earth might not be a perfect sphere, spherical is interpreted imprecisely enough so that near spheres fall within its pragmatic halo and are pragmatically ignorable.

Pragmatic halos can be modified by what Lasersohn calls "slack regulators." These modifiers work to contract the size of the halo - in other words, to allow less pragmatic slack and require more precision in how a statement is interpreted. If the slack regulator all is used as in (18) in a situation where townspeople are known to be awake, the sentence is false and recognized by hearers as infelicitous. Similarly for the slack regulators exactly and perfectly in (19) and (20), respectively, which shrink the pragmatic halo and require more precision in how the terms are interpreted.

(18) All the townspeople are asleep. (no exceptions allowed)

(19) It's exactly 3 o'clock. (cannot be uttered at 2:58pm)

(20) The earth is perfectly spherical. (recognized by hearers as false)

The manipulation of pragmatic halos will form an important part of the analysis in later sections, with sorta analyzed as widening a halo. But first, I introduce in the next section an implementation of Lasersohn's proposal using Hamblin semantics. 
Inherent and coerced gradability

\subsection{An alternatives-based implementation}

Morzycki (2011) provides an analysis of metalinguistic comparatives (see also McCawley 1998). Informally, metalinguistic comparatives compare how apt or appropriate a particular expression is. To characterize (21a), for example, what's being compared is the aptness or appropriateness of calling George dumb or crazy, and similarly in (21b), what's being compared is the appropriateness of calling Clarence a syntactician or semanticist.

(21) a. George is more dumb than crazy.

b. Clarence is a syntactician more than a semanticist.

Morzycki cashes out the descriptive generalization here in terms of imprecision. What's being compared is how precise it is to call George dumb or crazy. A degree parameter on the interpretation function $\llbracket . \rrbracket$ captures this, where higher degrees correspond to increased precision. I will call this the imprecision parameter or degree of imprecision. A metalinguistic comparative, then, compares the degree of imprecision between two expressions. This is demonstrated informally in (22). ${ }^{13}$

$\llbracket$ George is more dumb than crazy $\rrbracket^{d^{\prime}}$

$=\left(\lambda d\right.$. $\llbracket$ George is dumb $\left.\rrbracket^{d}\right)>\max \left(\lambda d\right.$. $\llbracket$ George is crazy $\left.\rrbracket^{d}\right)$

'The degree to which we can call George dumb is greater than the degree to which we can call George crazy.'

Morzycki suggests that imprecision here should be thought of in terms of Lasersohn's pragmatic halos. Halos are recast in terms of alternatives (Hamblin 1973; Kratzer \& Shimoyama 2002). Denotations themselves are identified with their pragmatic halo, with the imprecision parameter directly determining the size of the halo. The alternatives in the pragmatic halo are built from a primitive relation $\approx$ "resembles," which compares the degree to which two predicates of the same type resemble each other. This is defined in (23).

$\alpha \approx_{d, C} \beta$ iff, given the ordering imposed by the context $C, \alpha$ resembles $\beta$ to (at least) the degree $d$ and $\alpha$ and $\beta$ are of the same type (Morzycki 2011).

A denotation for dumb might look as in (24): a set of functions of type $\langle e t\rangle$ such that each function $f$ resembles dumb to at least degree $d$. (25) illustrates how the value of the imprecision parameter affects the size of the pragmatic halo. High

13 max can be defined as

(i) $\max (D)=\imath d\left[\forall d^{\prime}\left[D\left(d^{\prime}\right) \rightarrow d^{\prime} \leq d\right]\right]$ 
degrees decrease the size of the halo, while the maximum degree forces the halo to be a singleton.

$\llbracket d u m b \rrbracket^{d, C}=\left\{f_{\langle e t\rangle}: f \approx_{d, C} \mathbf{d u m b}\right\}$
a. $\llbracket d u m b \rrbracket^{1, C}=\{\mathbf{d u m b}\}$
b. $\llbracket d u m b \rrbracket^{9, C}=\{$ dumb, ignorant, dopey, foolish,$\ldots\}$
c. $\llbracket d u m b \rrbracket^{0, C}=D_{\langle e t\rangle}$

The lesson here is that we can think of Lasersohnian pragmatic halos as existing not in a post-compositional pragmatics, but as part of the compositional semantics. By providing a hook into pragmatic halos through the imprecision parameter and by modeling halos as alternatives, we are able to provide a compositional account of how pragmatic halos interact with the rest of the grammar.

\section{Analysis}

\subsection{Prelude}

The intuition I pursue here is to analyze sorta as a degree word, albeit one that is somewhat eccentric as far as degree words are concerned. The reason for this comes from sorta's cross-categorial behavior, combining with gradable and non-gradable adjectives as well as verbs and nouns. When combined with a gradable adjective, the reading available is akin to a degree reading. With non-gradable adjectives, verbs, and nouns, the reading becomes one of approximation to the predicate being modified. This suggests that, at its core, sorta is degree-related, but has special coercive powers when used with predicates without a gradable interpretation.

The coercive power here is a consequence of pragmatic halos being sets of alternatives that resemble some core function. The role of sorta is to increase the size of a pragmatic halo in order to bring in more functions that approximate some other function. Using Morzycki's alternative semantics for pragmatic halos allows us to keep a degree semantics for sorta with both non-gradable and gradable predicates. Gradable predicates lexicalize degree arguments, which sorta can saturate. For non-gradable predicates, sorta's combinatorial need to combine with a gradable predicate forces a typeshift. The effect of this typeshift is to make non-gradable predicates gradable by using their imprecision parameter as a degree argument. In this way, sorta can saturate the new degree of precision argument of a non-gradable predicate.

Before beginning the analysis, I should state my assumptions. I assume an ontology with degrees, abstract units of measurement (Kennedy 1999; Seuren 1973; Schwarzschild \& Wilkinson 2002; von Stechow 1984). I also assume that gradable 
adjectives such as tall lexicalize degree arguments and are relations between degrees and individuals (as in (27)). This move makes adjectives by themselves incomplete; they need to be saturated with a degree. A null morpheme POS is assumed to be present in the unmarked (absolutive) constructions (Cresswell 1976; von Stechow 1984; Bierwisch 1989; Kennedy 1999). The function of POS is to existentially quantify over degrees and supply a degree that meets a contextually supplied standard. For a gradable adjective, this makes it so that not only does someone have some height (which mere existential quantification over a degree would give you), but that someone also meets the standard. This matches our intuitions for what tall means; to be tall isn't to have just any height, but to meet the height for which we would call someone tall. A function standard is used in the semantics, which takes a gradable predicate as an argument and returns the degree in the context which represents the standard. Here, POS is assumed to be a Deg head, DegP being the extended projection of AP (Abney 1987; Kennedy 1999; Corver 1990; Grimshaw 1991). This is illustrated in (26-29).

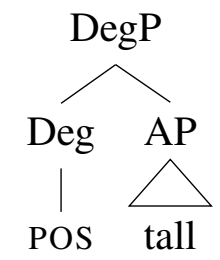

$$
\begin{aligned}
& \llbracket \text { tall } \rrbracket=\lambda d \lambda x[\operatorname{tall}(d, x)] \\
& \llbracket \mathrm{POS} \rrbracket=\lambda G_{\langle d, e t\rangle} \lambda x \exists d[d \geq \operatorname{standard}(G) \wedge G(d)(x)] \\
& \llbracket \mathrm{POS} \text { tall } \rrbracket=\lambda x \exists d[d \geq \operatorname{standard}(\llbracket \operatorname{tall} \rrbracket) \wedge \operatorname{tall}(d, x)]
\end{aligned}
$$

Because I am working in a Hamblinized system, denotations will often be sets of alternatives rather than functions. Assuming Morzycki's imprecision parameter and representing denotations with their halos, tall might be translated as in (30). The analysis will start without alternatives, but alternatives will be added when necessary.

$$
\llbracket t a l l \rrbracket^{d^{\prime}, C}=\left\{f_{\langle d, e t\rangle}: f \approx_{d^{\prime}, C} \lambda d \lambda x . \operatorname{tall}(d, x)\right\}
$$

Finally, it will be crucial for me to have access to the imprecision parameter. Following Morzycki, I assume a typeshift PREC, defined in (31) below.

$$
\llbracket \operatorname{PREC} \alpha \rrbracket^{d}=\lambda d^{\prime}
$$

The PREC typeshift binds the imprecision parameter, turning any expression type $\langle\tau\rangle$ into a function type $\langle d \tau\rangle$. When necessary, I'll label PREC as a node in the syntax. 


\subsection{Sorta and gradable adjectives}

In previous sections, I highlight how sorta behaves as a degree word. I will consider it a degree word at heart and analyze it as one might analyze another degree word such as very. The syntactic assumption here will be that sorta heads a DegP, much like POS or very do under certain analyses, with an AP headed by a gradable adjective as its complement, as in (32). DegPs are predicative and are properties of individuals, and by assumption APs are relations between degrees and individuals. Syntactically and type-theoretically, this makes sorta comparable to POS.

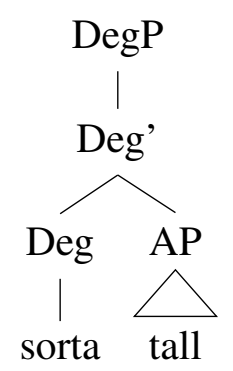

How might we think about the semantic content of sorta? The natural move here is to keep the parallelism between sorta and POS; sorta should be of the same logical type as POS, as well as do something similar semantically. POS asserts the existence of a degree such that that degree meets a contextually provided standard, as well as saturating the individual and degree arguments of the AP it combines with. The entailment to the standard with sorta is murky, however; what we might do here is say that the degree quantified over is simply close to the standard. I define a 'close to' relation in (33), such that, for two degrees $d$ and $d^{\prime}, d \lessdot d^{\prime}$ is true just in case $d$ and $d^{\prime}$ are close to each other, as defined by the context and a gradable predicate. Sorta is defined as in (34), where $\alpha$ is a gradable adjective (type $\langle d$, et $\rangle$ ). ${ }^{14}$

$\forall d \forall d^{\prime}, d \lessdot_{C, P} d^{\prime}$ iff the value of $d$ is close to $d^{\prime}$ as determined by the context $C$ and a gradable predicate $P$.

$$
\llbracket \operatorname{sorta} \alpha \rrbracket^{C}=\lambda x \exists d\left[d \lessdot_{C, \llbracket \alpha \rrbracket} \operatorname{standard}(\llbracket \alpha \rrbracket) \wedge \llbracket \alpha \rrbracket(d)(x)\right]
$$

(35) demonstrates how sorta tall would work. For readability, I've suppressed the parameters on $\lessdot$ and the argument to standard.

Bill is sorta tall.

14 Intuitively, sorta can be thought of as a function from relations between degrees and individuals to properties of individuals, a function type $\langle\langle d, e t\rangle$,et $\rangle$. Unconventionally, I define sorta syncategormatically here rather than as a function, meaning sorta doesn't have that type, formally speaking. Defining sorta in this way will be required when alternatives are added to the analysis in the next section. 
Inherent and coerced gradability

$$
\begin{aligned}
& \text { a. } \llbracket \text { sorta } \alpha \rrbracket^{C}=\lambda x \exists d[d \lessdot \operatorname{standard} \wedge \llbracket \alpha \rrbracket(d)(x)] \\
& \begin{aligned}
& \text { b. } \llbracket \text { sorta tall } \rrbracket^{C} \\
& \quad=\lambda x \exists d[d \lessdot \operatorname{standard} \wedge \llbracket \operatorname{tall} \rrbracket(d)(x)] \\
& \quad=\lambda x \exists d[d \lessdot \operatorname{standard} \wedge \operatorname{tall}(d, x)]
\end{aligned} \\
& \text { c. } \llbracket \text { sorta tall } \rrbracket^{C}(\llbracket \text { Bill } \rrbracket)=\exists d[d \lessdot \operatorname{standard} \wedge \operatorname{tall}(d, \mathbf{b})]
\end{aligned}
$$

To summarize, sorta can be analyzed as a variety of degree word using the standard tools from degree semantics. Syntactically and semantically, we can think of it as a cousin to POS, but rather than asserting that a degree exceeds the standard, sorta requires that a degree be close to the standard. The analysis here will form the core of the analysis of sorta with non-gradable predicates in the next section.

\subsection{Sorta and non-gradable predicates}

In the previous section I analyze sorta as a variety of degree word. The role of sorta is to assert that a degree is close to the contextually provided standard and to saturate the degree argument of the gradable predicate it combines with. If some predicate has a degree argument, this would be satisfactory. The issue that arises, though, is that most verbs and nouns aren't usually argued to lexicalize a degree argument. If sorta is a degree word, we need to ask what degree it is operating over when combined with non-degree predicates.

The clue that we can extend a degree analysis to non-gradable predicates comes from the approximative flavor of sorta. Recalling previous observations, constructions involving sorta and non-gradable predicates can be conveniently paraphrased with approximatives such as close to or like, as in (36). The way to look at the degree that sorta operates over with non-gradable predicates should be as a degree that represents how closely one predicate approximates another.

a. I sorta kicked the ground.

'I did something like kicking the ground.'

b. He sorta swam over to the boat.

'He did something that was like swimming over to the boat.'

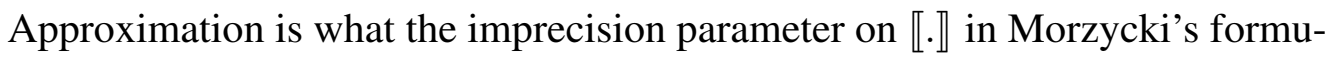
lation of pragmatic halos represents - a degree that represents how much objects in the pragmatic halo are allowed to approximate some object. A high degree of precision is a way of forcing objects in the pragmatic halo to more closely approximate some object, while increasingly lower degrees allow for less precision and correspondingly looser approximations. This approximation is accomplished with a relation $\approx$, which is true just in case two semantic objects resemble each other 
to at least some degree $d$. The interpretations of constructions involving sorta and non-gradable predicates also suggest that looking at approximation in this way is on the right track. Intuitively, a construction with sorta, like sort of swim, involves something that resembles the modified verb in some way.

Little speech is perfectly precise; swim can be used in many different ways that approximate a core concept of swimming (whatever that may be). What should be said here, then, is that sorta swim (for example) isn't necessarily approximate to swim, but approximate to what 'counts' as swimming in the context. Needed here is a notion of standards that includes not just the standards associated with adjectival scales, but also with degrees of precision. Drawing up the degree analysis of sorta from the previous section, the degree that sorta introduces must be close to the standard degree of precision for the context.

What I will assume is that the standard function is defined not only to return standards associated with adjectival scales, but also standards associated with the degree of precision. This requires no change in the logical types of arguments to standard. For adjectival scales, standard takes a gradable adjective (type $\langle d, e t\rangle$ ) as an argument. For degrees of precision, standard can also take a function type $\langle d, e t\rangle$, a property coerced into the type of a gradable predicate by way of the PREC typeshift (as demonstrated in (37)).

$$
\begin{aligned}
& \llbracket \text { PREC swim } \rrbracket^{d} \\
& =\lambda d^{\prime} . \llbracket \text { swim } \rrbracket^{d^{\prime}} \\
& =\lambda d^{\prime} \cdot\left\{f_{\langle e t\rangle}: f \approx_{d^{\prime}, C} \mathbf{s w i m}\right\}
\end{aligned}
$$

With this in mind, what sorta does is existentially quantify over a degree close to the standard degree of precision. This has the effect of lowering the degree of precision, in turn widening the pragmatic halo. ${ }^{15}$ Because we are dealing with alternatives now, our definition of sorta must be adjusted in order to pick a single alternative from the halo and apply it to the individual argument of sorta, as well as set the imprecision parameter to the new degree of precision. (38) reflects these changes, where $\alpha$ represents a predicate turned into a gradable predicate by way of PREC (as in 39-40).

$$
\llbracket \operatorname{sorta} \alpha \rrbracket^{d^{\prime}, C}=\lambda x \exists d\left[d \lessdot_{C, \llbracket \alpha \rrbracket} \operatorname{standard}(\llbracket \alpha \rrbracket) \wedge \exists f: f \in \llbracket \alpha \rrbracket(d)[f(x)]\right]
$$

15 One issue here is that $\lessdot$ only requires two degrees to be close. A plausible solution to why sorta seems to widen the halo would involve some reasoning on behalf of the hearer; because the speaker used sorta and not the competing utterance without sorta, they must have meant for an adjustment in the size of the pragmatic halo. 
Inherent and coerced gradability

(39)

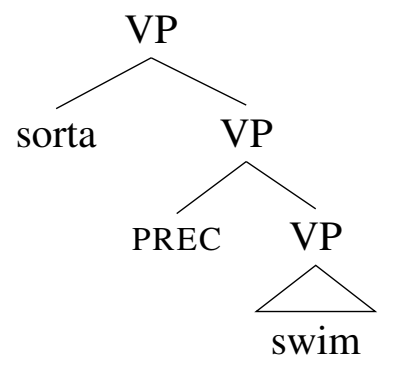

(40)

$$
\begin{aligned}
& \llbracket \text { sorta }[\text { PREC swim }] \rrbracket^{d^{\prime}, C}= \\
& \lambda x \exists d\left[\begin{array}{l}
d \lessdot_{C, \llbracket \text { PREC swim } \rrbracket} \text { Standard }(\llbracket \text { PREC swim } \rrbracket) \wedge \\
\exists f: f \in \llbracket \text { PREC swim } \rrbracket(d)[f(x)]
\end{array}\right]
\end{aligned}
$$

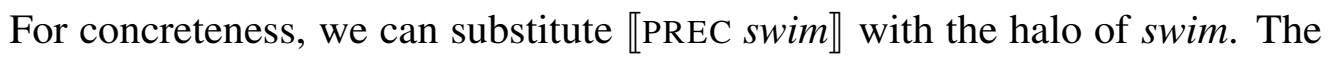
degree argument of $\llbracket$ PREC swim $\rrbracket$ is saturated by $d$, creating a set of alternatives that represent swim to at least degree $d$, as demonstrated in (41). Examples of these alternatives are explicitly represented in (42). Arguments have been suppressed where possible for readability.

$$
\begin{aligned}
& \llbracket(39) \rrbracket^{d^{\prime}, C}=\lambda x \exists d\left[\begin{array}{l}
d \lessdot \mathbf{s t a n d a r d} \wedge \\
\exists f: f \in\left\{f_{\langle e t\rangle}: f \approx_{d, C} \mathbf{s w i m}\right\}[f(x)]
\end{array}\right] \\
& \llbracket(39) \rrbracket^{d^{\prime}, C}=\lambda x \exists d\left[d \lessdot \text { standard } \wedge \exists f: f \in\left\{\begin{array}{c}
\text { swim, } \\
\text { float, } \\
\text { wade, } \\
\ldots
\end{array}\right\}[f(x)]\right.
\end{aligned}
$$

As mentioned in section 3, sorta $V$ does not have entailments to $V$. The reasons for this are now apparent; because the halo around the verb was expanded, there are many functions within the halo that sorta can choose from. Not all of these options are within the original halo of the verb, as set by the standard degree of precision. Since sorta is free to choose any function, the entailment to the verb disappears.

To summarize here, sorta does a couple of things. First, it existentially quantifies over degrees that are close to the standard degree of precision for the context, with the purpose of widening the pragmatic halo of the object it is combined with. As sorta requires a gradable predicate to combine with, non-gradable predicates are coerced into gradable predicates via the PREC typeshift. Next, the degree of precision of the non-gradable predicate that sorta is combined with is set to the degree quantified over by sorta. This creates a set of alternatives that at least $d$-resemble the predicate that sorta is modifying. Finally, a function is picked from this halo and applied to the individual argument of sorta. Although the examples above are for verb phrases of type $\langle e t\rangle$, we can see that this will generalize to other expressions that are property-denoting, including nouns and non-gradable adjectives. 
Curt Anderson

\subsection{Revisiting gradable adjectives}

In section 5.2, sorta is analyzed as a degree word. In section 5.3, this analysis is further developed so that sorta can play a degree role in the absence of a lexicalized degree. Two technical moves make this work: the PREC typeshift is applied to a non-gradable predicate in order to coerce gradability where none existed before, essentially building a gradable predicate out of a non-gradable one, and sorta existentially quantifies over a set of alternatives in order to pick a single alternative.

The question that needs to be answered here is whether the move of making sorta sensitive to alternatives creates any problems for the original analysis of sorta as a degree word. The answer, thankfully, is no; we're allowed the same analysis of sorta with both gradable and non-gradable predicates.

A Hamblinized denotation for tall might look as in (43). Somewhat unconventionally for this paper, I've translated tall as a singleton set rather than using the set builder notation and $\approx$. One reason for this is purely expository, a wish to keep the moving parts to a minimum. However, there is also a less innocent but more interesting reason here as well: it's simply not clear what the alternatives to tall would be here, at least under normal circumstances. Whether and what alternatives scalar adjectives have is a question that deserves further study.

$$
\llbracket t a l l \rrbracket^{d^{\prime}}=\{\lambda d \lambda x \cdot \operatorname{tall}(d, x)\}
$$

Although this is a set of alternatives rather than a function, in the alternative semantics it is still typed as $\langle d, e t\rangle$. This makes it the appropriate type to combine with sorta (see 44).

$$
\llbracket \text { sorta tall } \rrbracket^{d^{\prime}, C}=\lambda x \exists d[d \lessdot \operatorname{standard} \wedge \exists f: f \in \llbracket \operatorname{tall} \rrbracket(d)[f(x)]]
$$

One compositional wrinkle here: $\llbracket \operatorname{tall} \rrbracket(d)$ isn't well-formed, strictly speaking, due to $\llbracket t a l l \rrbracket$ being a set and $d$ being a degree. To make this work, I'll assume a principle whereby $d$ can be converted into the singleton set $\{d\}$. If $d$ can be converted into $\{d\}$, then $\llbracket$ tall $\rrbracket(\{d\})$ is perfectly coherent, if we assume a rule of Hamblin function application where functions from one set are applied pointwise to the arguments in a second set (Kratzer \& Shimoyama 2002; Morzycki 2011).

\section{Conclusion}

The fact that sorta was able to appear across categories, appearing with gradable and non-gradable adjectives, verbs, and even nouns, might have led us to believe that all these categories had some common semantics, namely some sort of inherent gradability. Based on the meanings that constructions involving sorta are able to take, however, I've argued that this isn't the case. Rather, what ties these categories 
together is sorta itself; sorta has a degree semantics that, when coupled with a specialized typeshift PREC, allows it to grade over both gradable and non-gradable predicates. Gradable adjectives receive rather pedestrian degree readings. Nongradable predicates are coerced into gradable predicates; sorta lowers the degree of precision in order to expand a Lasersohnian pragmatic halo, and picks a function from this halo.

The benefit of this system is that it provides a unified picture of how sorta works: across categories, sorta maintains a degree semantics, but the degree used differs depending on the lexical semantics of the predicate modified. Gradable adjectives are inherently gradable, by virtue of lexicalizing a degree argument. However, non-gradable predicates are only externally gradable; they must be coerced into having a scalar semantics. This gives us a clearer picture of what gradability is and where to find it; while inherent gradability might be limited, we should expect to find places where gradability has been coerced. Looking at the semantics of modifiers such as sorta may give us clues as to when gradability has been coerced or when it is inherent.

Finally, this work also deeply depends on aspects of the pragmatic system being available in the compositional semantics, namely pragmatic halos. This is due to the truth-conditional effects of sorta (namely the weakening of entailments with non-gradable predicates). Sorta requires that the halo play a role in determining the truth conditions of the sentence. Furthermore, ways of manipulating the halo grammatically also need to be present in the semantics, providing hooks for modifiers like sorta to latch onto. This suggests that pragmatics and semantics may be quite intertwined, with no clear division of labor between the two.

\section{References}

Abney, Steven. 1987. The English noun phrase in its sentential aspect: MIT PhD thesis.

Bierwisch, Manfred. 1989. The semantics of gradation. In M. Bierwisch \& E. Lang (eds.), Dimensional Adjectives, 71-261. Berlin: Springer.

Bolinger, Dwight. 1972. Degree Words. The Hague: Mouton.

Corver, Norbert. 1990. The syntax of left branch extractions: Tilburg University $\mathrm{PhD}$ thesis.

Cresswell, Max J. 1976. The semantics of degree. In B. Partee (ed.), Montague Grammar, 261-292. New York: Academic Press.

Davies, Mark. 2008. The Corpus of Contemporary American English: 450 million words, 1990-present. Available online at http://corpus.byu.edu/coca.

Grimshaw, Jane. 1991. Extended projection. Ms., Brandeis University. 
Hamblin, Charles. 1973. Questions in Montague English. Foundations of Language 10(1). 41-53.

Kennedy, Chris. 1999. Projecting the Adjective: the Syntax and Semantics of Gradability and Comparison. New York: Garland Press.

Kratzer, Angelika \& Junko Shimoyama. 2002. Indeterminate pronouns: The view from Japanese. In Yukio Otsu (ed.), Third Tokyo Conference on Psycholinguistics, 1-25. Tokyo: Hituzi Syobo.

Lakoff, George. 1973. Hedges: A study in meaning criteria and the logic of fuzzy concepts. Journal of Philosophical Logic 2(4). 458-508.

Lasersohn, Peter. 1999. Pragmatic halos. Language 75(3). 522-551.

McCawley, James D. 1998. The Syntactic Phenomena of English. University of Chicago Press.

Morzycki, Marcin. 2011. Metalinguistic comparison in an alternative semantics for imprecision. Natural Language Semantics 19(1). 39-86.

Schwarzschild, Roger \& Karina Wilkinson. 2002. Quantifiers in comparatives: A semantics of degree based on intervals. Natural Language Semantics 10(1). $1-41$.

Seuren, Pieter. 1973. The comparative. In Ferenc Kiefer \& Nicolas Ruwet (eds.), Generative Grammar in Europe, 528-564. Dordrecht: D. Reidel.

von Stechow, Arnim. 1984. Comparing semantic theories of comparison. Journal of Semantics 3(1). 1-77.

Curt Anderson

B331 Wells Hall

Michigan State University

East Lansing, MI 48824

ande1472@msu.edu 